\title{
Hypertrophic cardiomyopathy and ultra- endurance running - two incompatible entities?
}

\author{
Mathew G Wilson ${ }^{1}$, Navin Chandra ${ }^{2}$, Michael Papadakis ${ }^{2}$, Rory O'Hanlon ${ }^{3}$, Sanjay K Prasad ${ }^{4}$ and Sanjay Sharma ${ }^{*}$
}

\begin{abstract}
Regular and prolonged exercise is associated with increased left ventricular wall thickness that can overlap with hypertrophic cardiomyopathy (HCM). Differentiating physiological from pathological hypertrophy has important implications, since HCM is the commonest cause of exercise-related sudden cardiac death in young individuals. Most deaths have been reported in intermittent 'start-stop' sports such as football (soccer) and basketball. The theory is that individuals with HCM are unable to augment stroke volume sufficiently to meet the demands of endurance sports and are accordingly 'selected-out' of participation in such events. We report the case of an ultraendurance athlete with 25 years of $>50 \mathrm{~km}$ competitive running experience, with genetically confirmed HCM; thereby demonstrating that these can be two compatible entities.
\end{abstract}

Keywords: Ultra-endurance exercise, hypertrophic cardiomyopathy, athlete?'?s heart, sudden cardiac death, pre-participation screening

\section{Background}

Regular physical exercise is associated with physiological increases in cardiac dimensions which may be reflected on the electrocardiogram (ECG). Differentiating a physiological or pathological remodelling mechanism is important, as significant cardiac enlargement may be an expression of underlying cardiac disease, placing the athlete at a greater risk of sudden cardiac death (SCD) [1]. Approximately $80 \%$ of non-traumatic sudden deaths in young athletes $(<35$ years) are caused by inherited or congenital structural and functional cardiovascular abnormalities, which provide a substrate for arrhythmias predisposing to SCD [2]. Hypertrophic cardiomyopathy (HCM), defined by the presence of increased ventricular wall thickness or mass in the absence of loading conditions (hypertension, valve disease, etc) sufficient to cause the observed abnormality [3], is the leading cause of SCD in the young and accounts for one third of all sudden cardiac deaths in young competitive athletes $[4,5]$. However, existing data also demonstrates that a small proportion of athletes $(<2 \%)$ exhibit increased left ventricular wall thickness (LVWT) ranging between 13-

\footnotetext{
* Correspondence: sanjay.sharma091064@googlemail.com

${ }^{2}$ St George's University of London, Division of Cardiac \& Vascular Sciences, London, UK

Full list of author information is available at the end of the article
}

$16 \mathrm{~mm}[6-8]$, which overlaps with morphologically mild HCM.

Deaths from HCM are predominantly confined to intermittent 'start-stop' sports such as American football, basketball and soccer, with few cases reported in endurance sports. The postulated theory is that individuals with $\mathrm{HCM}$ are unable to augment cardiac output sufficiently to participate in intensive and prolonged endurance sports due to a combination of pronounced $\mathrm{LVH}$, a non-compliant LV, exercise-induced LV outflow obstruction and microvascular ischemia. However, we report an ultraendurance athlete with confirmed HCM capable of performing high-levels of aerobic ultra-endurance activity.

\section{Case Presentation}

A 44 year-old Caucasian male was evaluated in our centre for investigation of a cardiac murmur identified by his primary care physician. The individual was asymptomatic with no past medical history, medication history or family history. He was an ultra-marathon runner with over 25 years of competitive running history; currently participating in 3 ultra-marathon $(>50 \mathrm{~km})$ events per year often involving challenging mountainous and frozen terrain. Resting blood pressure of $95 / 60 \mathrm{mmHg}$ and physical examination was unremarkable apart from the presence of a soft ejection systolic murmur.

\section{() Biomed Central}


The ECG demonstrated first-degree heart block, right axis deviation, voltage criteria for bi-atrial enlargement, $\mathrm{LVH}$ and significant repolarisation anomalies including ST-segment depression in leads II, III and AVF, and deep T-wave inversions in leads V5 and V6 (Figure 1). Echocardiography demonstrated asymmetric septal hypertrophy of the basal and mid-septum with a maximal LVWT of $14 \mathrm{~mm}$ and an end-diastolic LV diameter of $44 \mathrm{~mm}$ (Figure 2a, 3a and 2b, 3b). There was no evidence of systolic anterior motion of the mitral valve leaflet or LV outflow tract obstruction. Systolic and diastolic function were clinically normal; the left atrial diameter measured $37 \mathrm{~mm}$, the E/A ratio was $>1$ (Figure 4) and tissue Doppler revealed an E' of $16 \mathrm{~cm} / \mathrm{s}$ at the lateral LV wall and $11 \mathrm{~cm} / \mathrm{s}$ in the septal LV wall (Figure 5).

Subsequent investigations included an exercise stress test with the athlete completing 21 minutes of the Bruce protocol (19.1 METS) corresponding to an oxygen consumption of $67 \mathrm{ml} / \mathrm{kg}^{-1} / \mathrm{min}^{-1}$. Heart rate $(91 \%$ predicted maximum) and BP response (systolic BP rising from 98 $\mathrm{mmHg}$ to $168 \mathrm{mmHg}$ at peak exertion) to exercise was normal and there was no evidence of cardiac dysrhythmias on exercise or on the 24-hour Holter monitor.

The abnormal resting ECG, asymmetric septal hypertrophy and non-dilated LV cavity raised suspicion of HCM. However, the normal indices of diastolic function and supra-normal functional capacity favoured 'athlete's heart'. Consequently, CMR was performed using standardised imaging protocols [9]. Analysis of the short axis images in diastole demonstrated asymmetrical hypertrophy predominantly affecting the basal and mid anteroseptal and inferoseptal walls (maximum wall thickness, $17 \mathrm{~mm}$ ). The lateral wall at the same level measured $8.5 \mathrm{~mm}$ (Figure $2 \mathrm{~b}, 3 \mathrm{~b}$ ). Imaging for late gadolinium enhancement (LGE) was performed approximately 10 minutes after contrast administration using an inversion-recovery gradient echo sequence. This demonstrated regions of focal intramyocardial fibrosis in the anterior and inferior basal LV-RV insertion points (Figure 6). The degree of focal fibrosis was felt to be disproportionate and not physiological. Insertion point fibrosis has been described in cases of hypertensive $\mathrm{LVH}$, aortic stenosis and congenital heart disease [10]. In this case however, there was no history of any of the above conditions and hence LGE was considered to represent cardiomyopathy.

Accordingly, first-degree relatives were invited to our centre for cardiovascular screening, which demonstrated an abnormal ECG and echocardiogram consistent with $\mathrm{HCM}$ in the mother and sister of the index case. Genetic testing for known mutations encoding sarcomeric contractile proteins proved positive for a mutation in the MYBPC3 gene encoding myosin binding protein

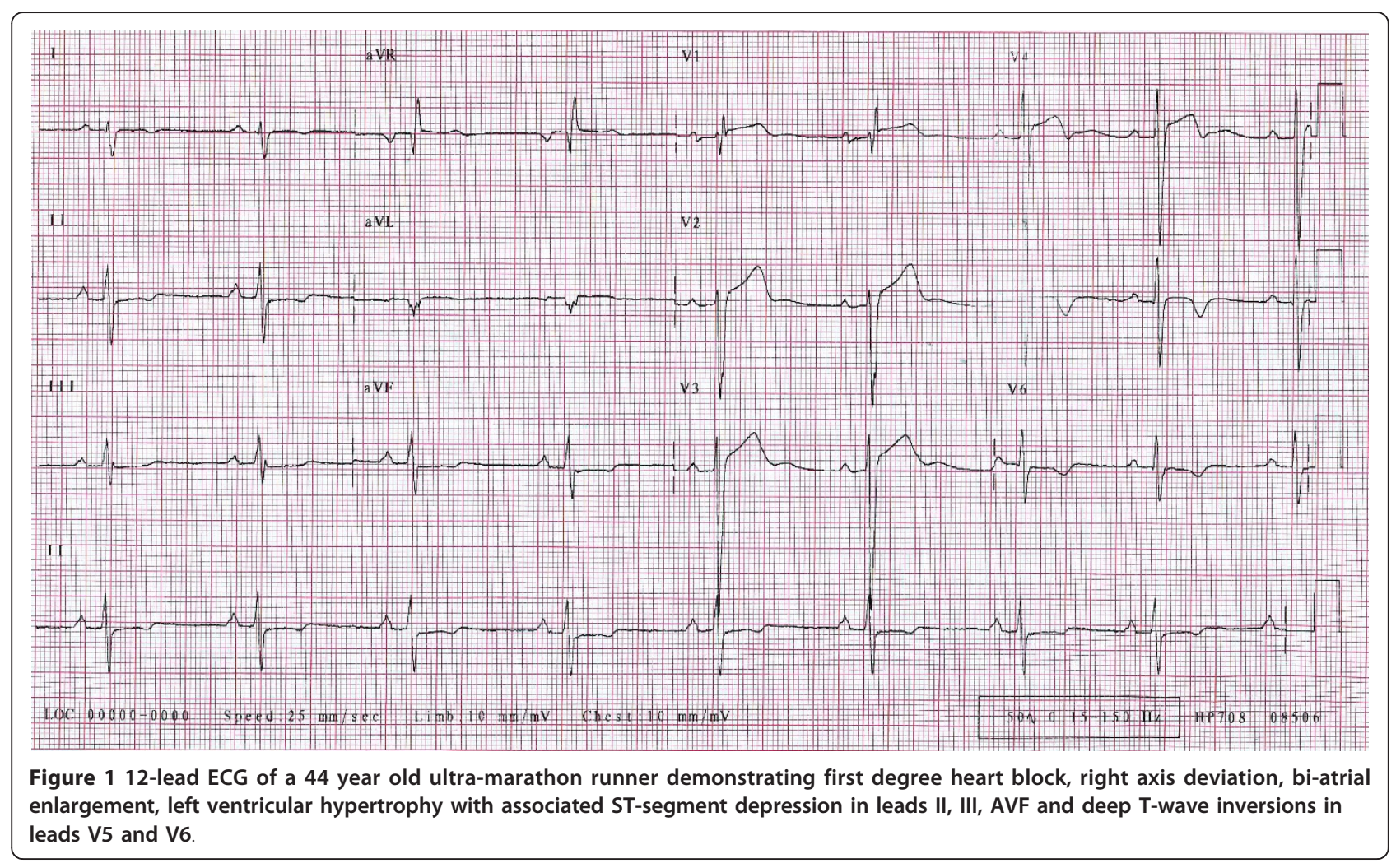



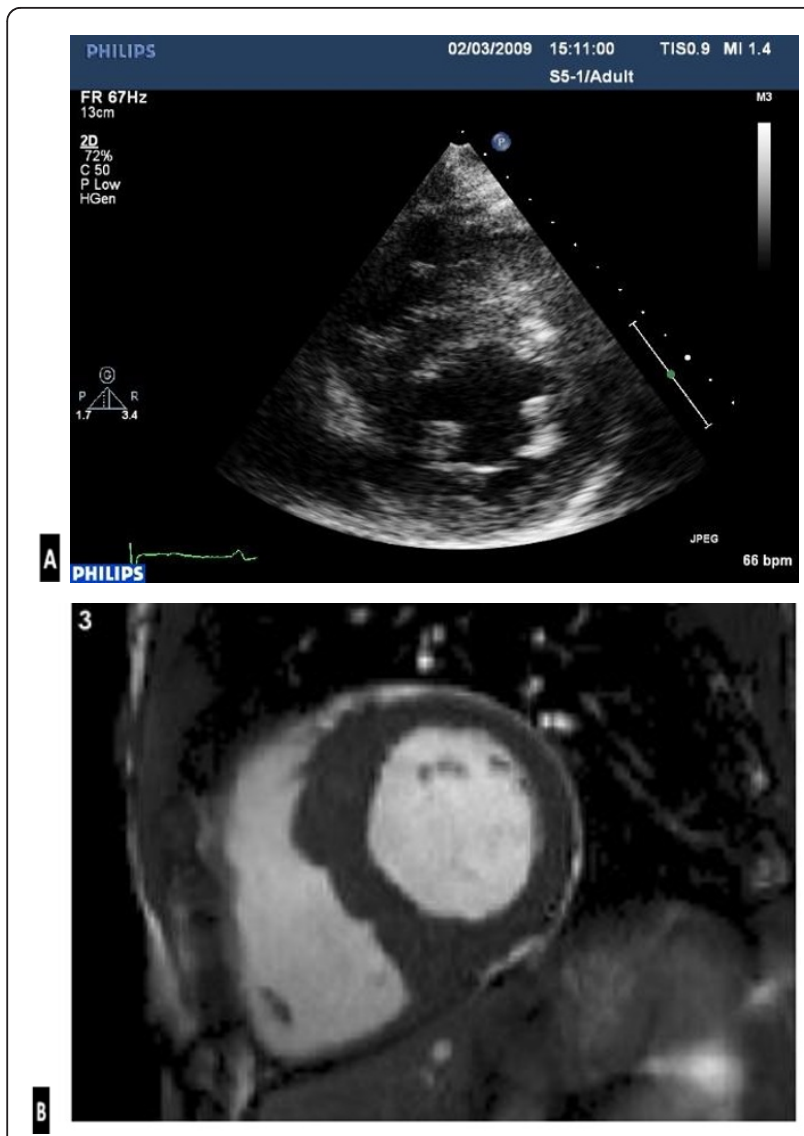

Figure 2 Trans-thoracic echocardiography (a) vs. CMR (b) image demonstrating; asymmetric septal hypertrophy of 14 $\mathrm{mm}$ and a left ventricular cavity size of $44 \mathrm{~mm}$ in the parasternal short axis at papillary muscle level (a) vs. asymmetric septal hypertrophy of $17 \mathrm{~mm}$, a left ventricular cavity size of $44 \mathrm{~mm}$ and a lateral wall of $8.5 \mathrm{~mm}$ at the same level (b)

C (specifically c.2096delC (p.Pro699fs) in MYBPC3 exon 22) in all three individuals.

\section{Discussion}

Previous cases of endurance athletes with HCM have been reported [11], however, this is the first case of a genetically proven diagnosis in an individual able to perform such high levels of ultra-endurance exercise for over 25 continuous years. This case demonstrates the challenges faced when evaluating athletes with an abnormal ECG or LV hypertrophy on echocardiography and highlights the importance of systematic evaluation that includes LGE-CMR to determine whether such changes represent physiological adaptation or pathological phenomena.

The ECG presented here has numerous features compatible with cardiac adaptation to exercise, including voltage criteria for $\mathrm{LVH}, \mathrm{ST}$-segment depression, a prolonged PR interval and inverted T-waves [6,12-17]. However, T-wave inversion in V5-6 are nearly always associated with cardiomyopathy and should always be interpreted with suspicion for three important reasons; 1) the ECG is abnormal in $95-97 \%$ of patients with HCM, 2) whereas voltage criteria for LVH are present in around $75 \%$ of patients with HCM, isolated SokolowLyon voltage criterion for LVH commonly observed within athletes (without associated ST and $\mathrm{T}$ wave changes) occurs in only $2 \%$ of HCM patients, and 3 ) repolarisation changes consisting of ST segment shift and $\mathrm{T}$ wave inversion are present in over $90 \%$ of cases.

Whilst echocardiography demonstrated a LVWT is 14 $\mathrm{mm}$ at the septum, it is well established that a minority of Caucasian athletes $(<2 \%)$ also demonstrate physiological LVH between 13-16 mm [7,8,18]. However, physiological LVH is typically associated with LV cavity dilatation of 55-65 mm. Hence, the LV cavity size of 44 $\mathrm{mm}$ in this case is unexpectedly reduced and typical of the disparity seen in individuals with HCM. Given the diagnostic uncertainty in this athlete, this case study also highlights the important role of including CMR in the workup of individuals presenting "grey zone" LVH (12-15 mm). There was a major discrepancy between maximal LV wall thickness derived by echocardiography $(14 \mathrm{~mm})$ and that of CMR $(17 \mathrm{~mm})$. Indeed, a wall thickness of $17 \mathrm{~mm}$ is not routinely observed within athletes regardless of body surface area $[7,8]$ and points ominously towards pathology. CMR provides a comprehensive assessment of both ischemic and non-ischemic cardiomyopathies providing detailed precise information on cardiac anatomy, function, tissue characterisation, epicardial and microvascular perfusion, valvular flows, and coronary and peripheral angiography. Measurements of maximal wall thickness are highly accurate, as is the pattern definition of LV wall thickening (focal vs. mild concentric) and unlike echocardiography, no geometrical assumptions need to be made about the ventricle $[19,20]$. Indeed, in some regions of the LV chamber, the extent of hypertrophy can be underestimated by echocardiography compared to CMR $[21,22]$, which is not diagnostically helpful in "grey zone" athletes. Finally, LGE provides a sensitive tool for the detection of myocardial fibrosis, abnormalities not typically seen in physiological LVH, thus highlighting pathology [23-25].

Due to the abnormal CMR and the abnormal cardiovascular evaluation of first-degree relatives, familial disease was presumed and genetic testing confirmed a diagnosis of HCM. Variable expression of the disease is common, even amongst members of the same family sharing the same gene defect. Mutations in more than 13 genes encoding sarcomeric contractile proteins have been identified as a cause of HCM [26]. Importantly, in a patient with an overt cardiomyopathy, the yield or 

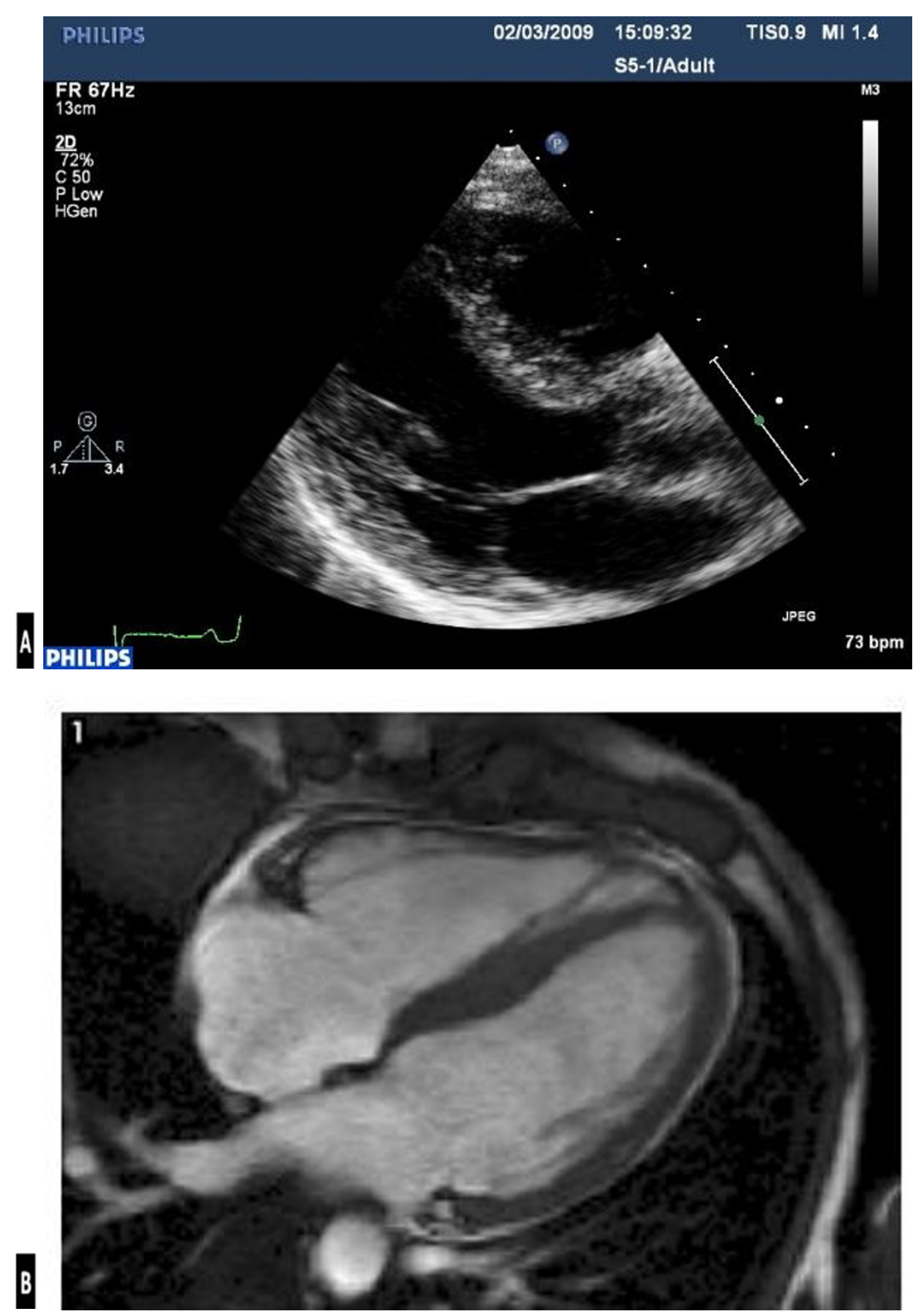

Figure 3 Trans-thoracic echocardiography (a) vs. CMR (b) image demonstrating; asymmetric septal hypertrophy of $14 \mathrm{~mm}$ and a left ventricular cavity size of $44 \mathrm{~mm}$ in the parasternal long axis at papillary muscle level (a) vs. asymmetric septal hypertrophy of 17 $\mathrm{mm}$, a left ventricular cavity size of $44 \mathrm{~mm}$ and a lateral wall of $8.5 \mathrm{~mm}$ at the same level (b).

rate of mutation identification is variable $(50-70 \%)$ [27]. Failure to identify a recognised mutation does not exclude the diagnosis of a cardiomyopathy for three important reasons; 1) not all genetic regions are assessed, 2) current technology is not able to detect some forms of mutation (intronic cryptic splice sites, large genomic rearrangements, etc), and 3) a similar phenotype may possibly develop without a specific 


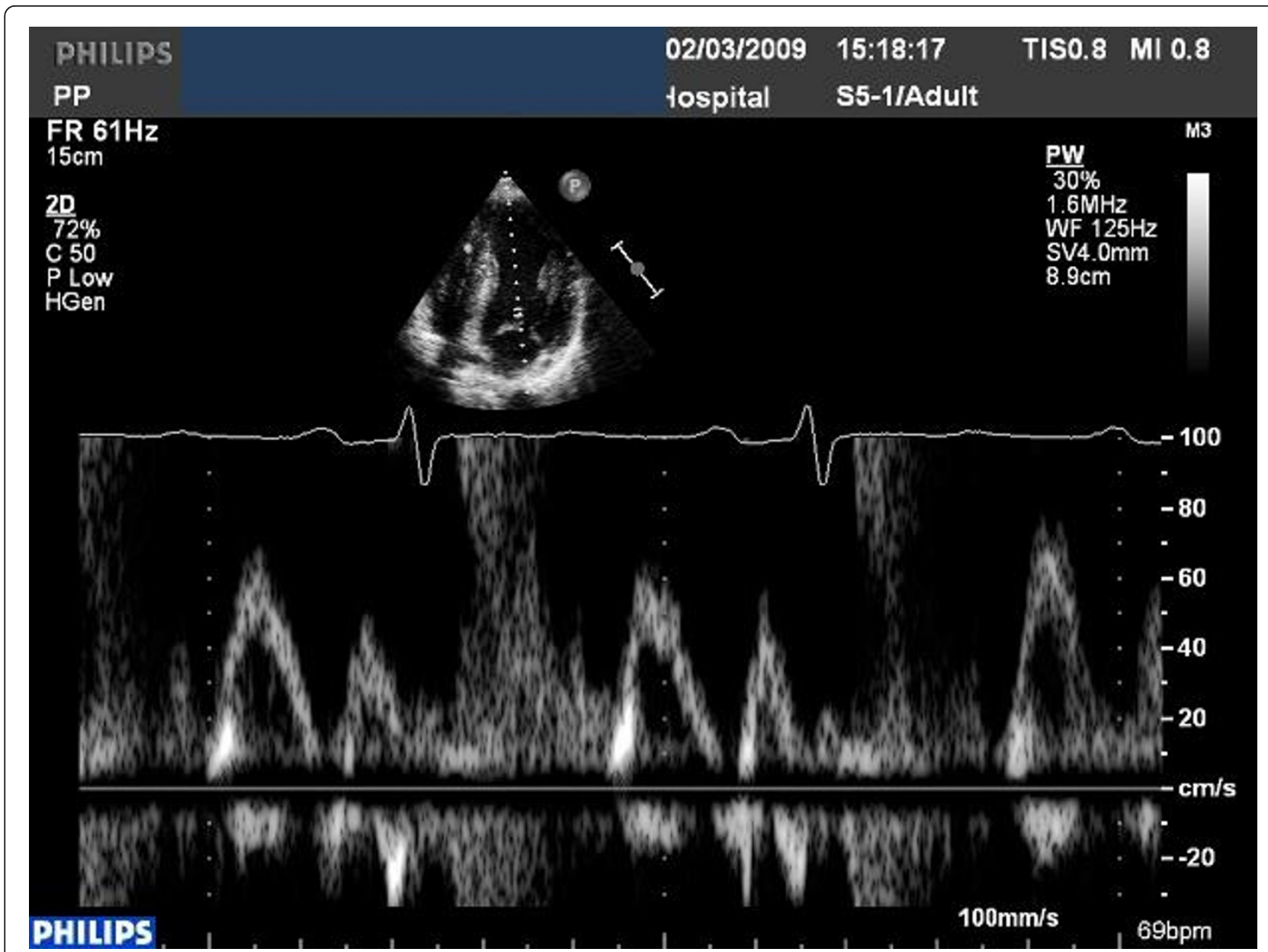

Figure 4 Normal indices of diastolic function; mitral inflow E:A ratio of $>1$.

genetic constitution. Lastly, it must be taken into account that genetic testing is expensive, not routinely available in most cardiology departments and can take up to 9 months to get a result. In our opinion, whilst the genetic test confirmed HCM, it was the abnormal electrocardiographic, imaging findings and family screening that confirmed genetic HCM rather than an athlete's heart. The clinical impression was that if a causative gene for HCM was not identified, the diagnosis of HCM would still have been made.

Recently, our laboratory recently examined the cardiac structure and function of a unique cohort of 12 asymptomatic truly life-long, competitive veteran endurance athletes ( $56 \pm 6 \mathrm{yr}$ ), with 20 age-matched veteran controls $(60 \pm 5 \mathrm{yr})$ and 17 younger male endurance athletes $(31 \pm 5 \mathrm{yr})$ using LGE CMR [28]. Veteran athletes had a significantly larger LV and RV end-diastolic and systolic volumes, intraventricular septum thickness during diastole [mean $\pm \mathrm{SD}$; (range) $11 \pm 1 \mathrm{~mm}(9-13 \mathrm{~mm})$ vs. $10 \pm 2 \mathrm{~mm}(10-13 \mathrm{~mm}), \mathrm{p}<$ $0.05]$ and posterior wall thickness during diastole $[10 \pm$
$1 \mathrm{~mm}(8-11 \mathrm{~mm})$ vs. $8 \pm 1 \mathrm{~mm}(7-10 \mathrm{~mm}) \mathrm{p}<$ 0.001], together with significantly reduced LV and RV ejection fractions $(\mathrm{p}<0.05)$, compared with veteran controls. We also observed the presence of myocardial fibrosis in $6(50 \%)$ of the veteran athletes, but no LGE in the age-matched veteran controls or young athletes. Importantly, the prevalence of LGE in veteran athletes was significantly associated with the number of years spent training $(\mathrm{p}<0.001)$, number of competitive marathons $(\mathrm{p}<0.001)$ and ultra-endurance $(>50$ miles) marathons $(\mathrm{p}<0.007)$ completed, suggesting a link between life-long endurance exercise and 'acquired' myocardial fibrosis that requires further investigation. However, the extent of $\mathrm{LVH}$ and fibrosis observed with these life-long veteran athletes was not as extensive as the athlete presented here, thus pointing towards a pathological mechanism.

Pre-participation screening data from Italy, incorporating the 12-lead ECG, suggests that the incidence of sudden death from HCM may be reduced through earlier identification and subsequent disqualification of 


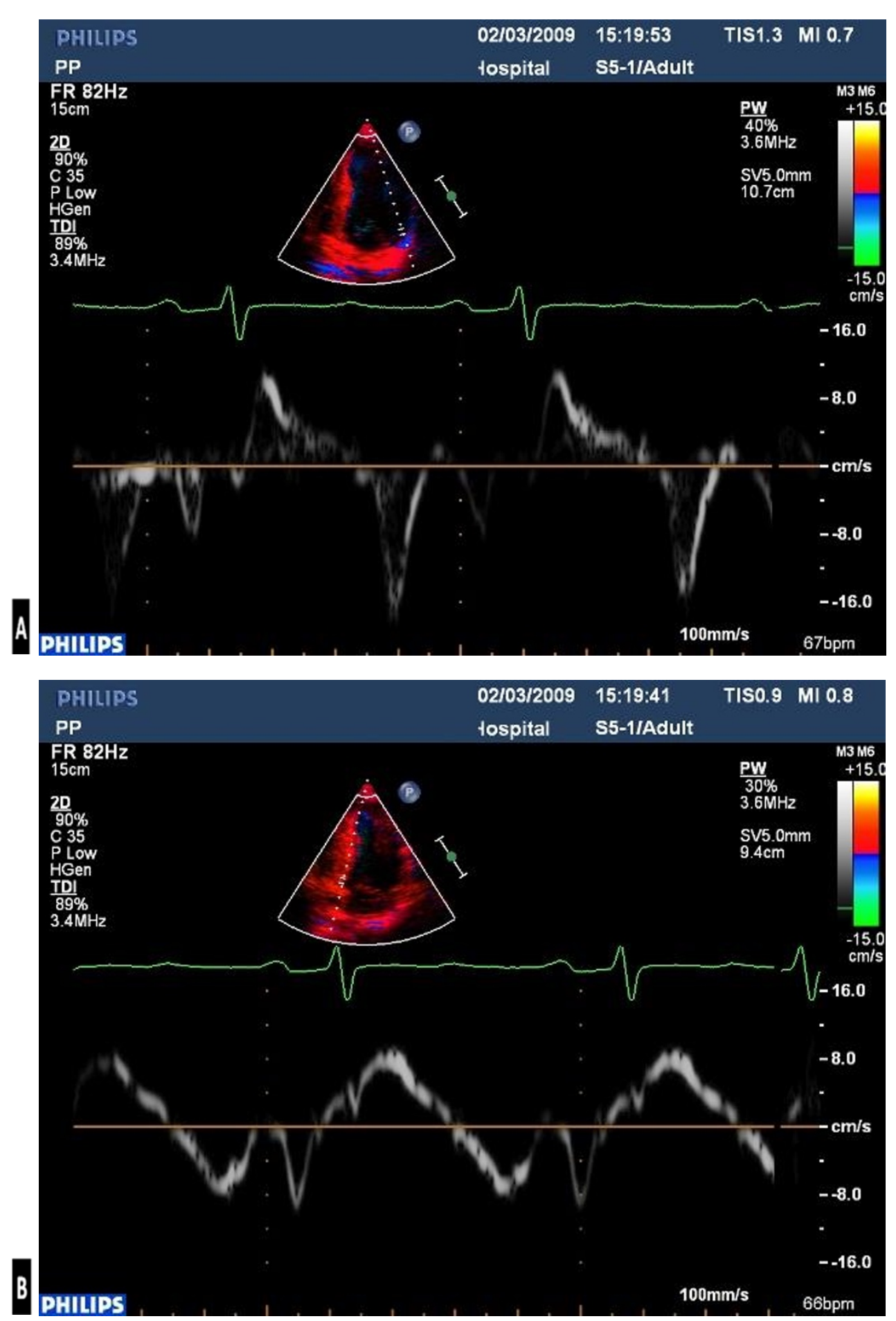

Figure 5 Tissue Doppler analysis of longitudinal function; with an $E^{\prime}$ of $16 \mathrm{~cm} / \mathrm{s}$ in the lateral LV wall (a) and $11 \mathrm{~cm} / \mathrm{s}$ in the septal LV wall (b).

affected athletes from competitive sport [29]. Guidelines from both the ACC 36th Bethesda Conference and ESC recommend that athletes with unequivocal or 'probable' HCM abstain from competitive sport and vigorous training with the exception of low-intensity activities [30-32]. The pathophysiology of death in an athlete with HCM during sport is multi-factorial; $\mathrm{HCM}$ has distinctive histology with affected areas of 

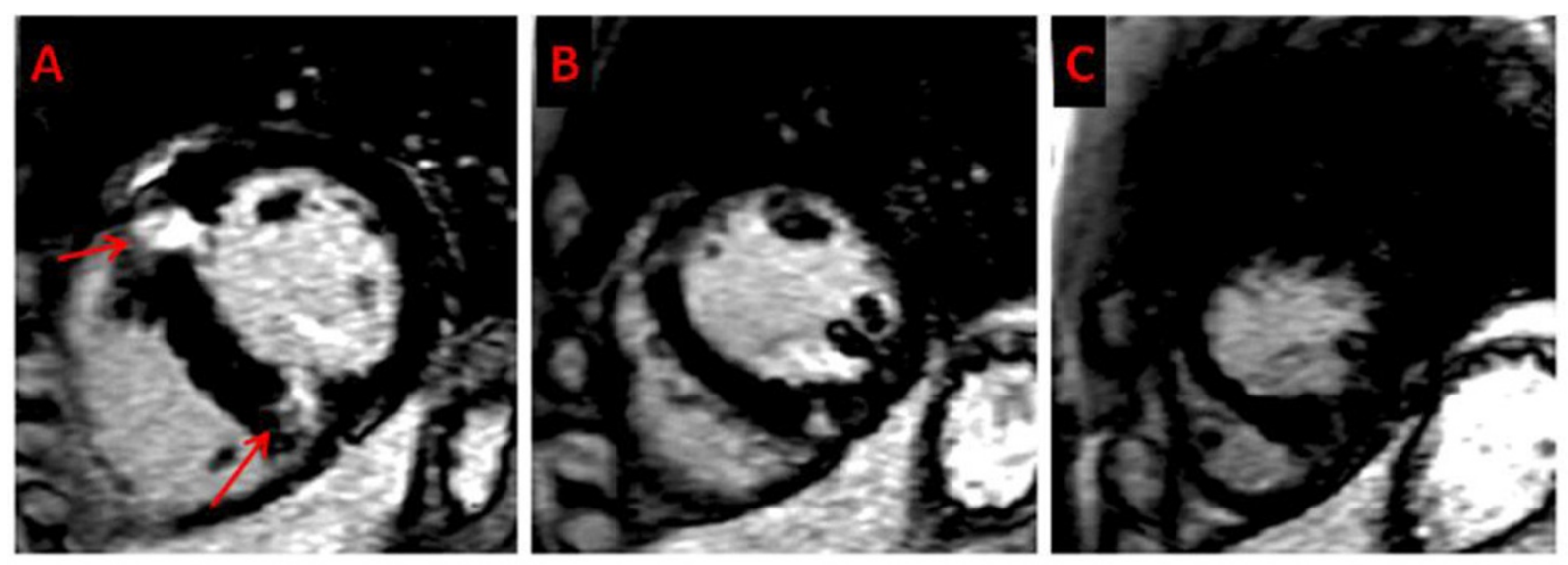

Figure 6 Late gadolinium enhancement $(A-C)$ at basal (A), mid (B), and apical(C) ventricular levels, demonstrating focal myocardial fibrosis (red arrows) predominantly at basal level in the basal anteroseptal and inferoseptal walls.

the myocardium demonstrating considerable interstitial fibrosis with gross disorganisation of the muscle bundles, resulting in a characteristic whorled pattern. In patients with HCM, the presence of fibrosis is an important marker of risk and patients with a greater number of risk factors for SCD typically have more fibrosis (as found in post-mortem data) [33], that is an independent risk for major adverse cardiac events [34]. The presence of fibrosis contributes to the disruption of the electrical synchrony that exists between myocytes and thereby increases arrhythmic potential $[35,36]$. Although a risk stratification algorithm for $\mathrm{HCM}$ is in existence, extrapolation of such data to an athletic milieu with associated high circulating catecholamines, acid-base shifts and electrolyte imbalances is unrealistic. Based on these considerations the exercise guidelines for this heterogeneous disorder are homogenous and conservative [37], and include athletes who may genuinely be at low risk of fatal cardiac events, as in this particular case.

Sporting disqualification from all high-intensity ultraendurance activity was discussed with the athlete together with ICD insertion. Personal and family genetic counselling together with clinical symptom education was given to the athlete regarding the risks of ultraendurance exercise and the potential for SCD. The athlete and family members agreed for genetic testing, but the athlete refused an ICD. Accordingly, the athlete is required to undergo a comprehensive yearly cardiovascular examination. However, the athlete continues to compete in ultra-endurance running events despite knowing the risks posed by continued high intensity competition; and with 2 years of follow-up data he remains asymptomatic without any significant cardiac changes.

\section{Conclusion}

This case study reports an asymptomatic male athlete with 25 years of ultra-endurance competition, with genetically confirmed HCM phenotypically manifesting with $\mathrm{LVH}$, a small LV cavity together with repolarisation abnormalities suggestive of HCM. Despite documented asymmetric hypertrophy and focal myocardial fibrosis in the basal anteroseptal and inferoseptal walls, it is suspected that the athlete is able to run ultra-marathons due to a compliant LV with normal diastolic and systolic parameters, which is able to augment stroke volume. In conclusion, rare as they might be, a minority of HCM patients are capable of life-long careers in ultraendurance exercise. This case also highlights the importance of systematic evaluation of all athletes with electrocardiographic features suggestive of a cardiomyopathy or ion channelopathy, with LGE CMR (Figure 7), maximal cardiopulmonary stress testing, firstdegree family screening and where appropriate, genetic testing, to determine whether such changes represent physiological adaptation or pathological phenomena.

\section{Consent}

Written informed consent was obtained from the patient for publication of this case report and any accompanying images. A copy of the written consent is available for review by the Editor-in-Chief of this journal.

\section{Funding}

Authors NC and MP are funded by a research grant from the charitable organisation 'Cardiac Risk in the Young' (Epson Downs, United Kingdom). SKP was supported by the NIHR Cardiovascular Biomedical Research Unit of the Royal Brompton and Harefield NHS Foundation Trust and Imperial College. 


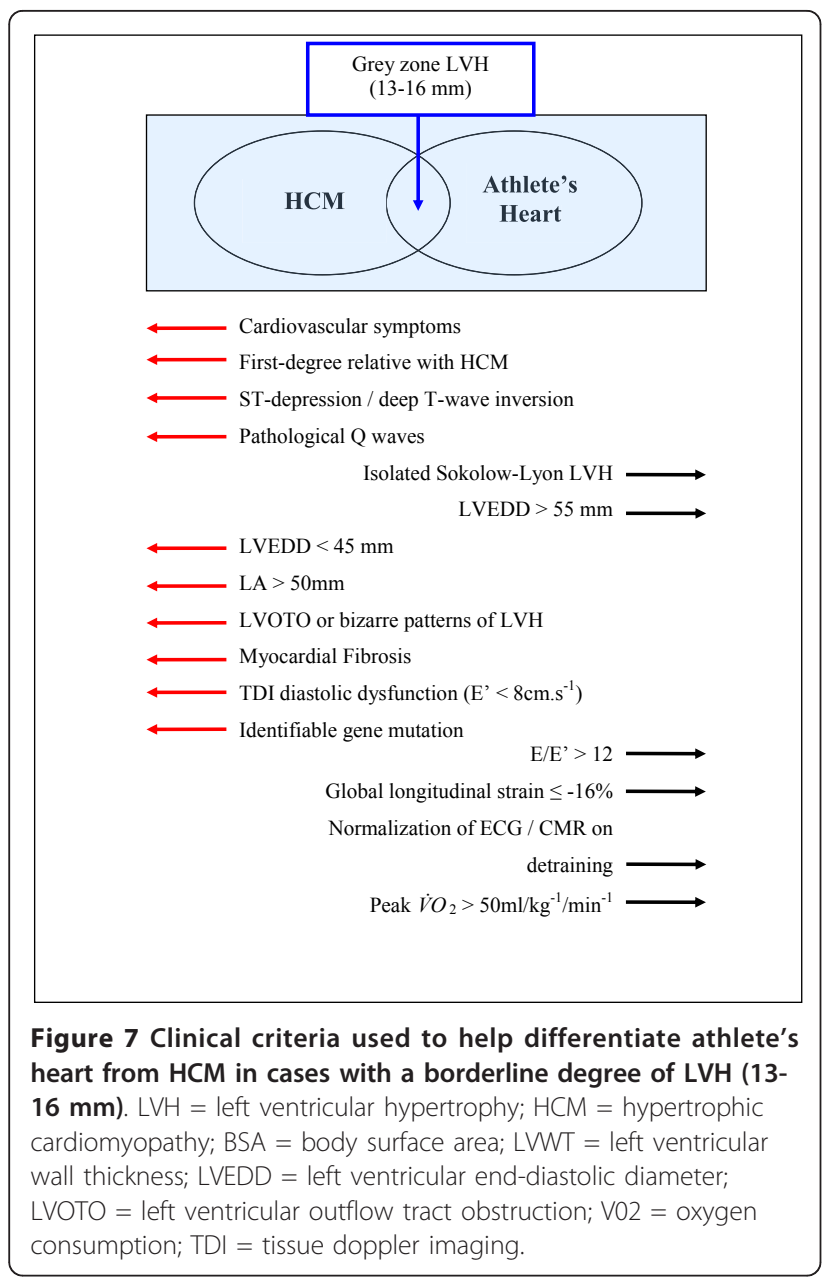

\section{Abbreviations}

HCM: Hypertrophic cardiomyopathy; SCD: Sudden cardiac death; LV: Left ventricle; LVH: Left ventricular hypertrophy; LVWT: Left ventricular wall thickness; CMR: Cardiac magnetic resonance.

\section{Author details}

'ASPETAR, Qatar Orthopaedic and Sports Medicine Hospital, Doha, Qatar. ${ }^{2}$ St George's University of London, Division of Cardiac \& Vascular Sciences, London, UK. ${ }^{3}$ St Vincent's University Hospital and The Blackrock Clinic, Dublin, Ireland. ${ }^{4}$ Royal Brompton and Harefield NHS Trust, London, UK.

\section{Authors' contributions}

MGW, NC and SS designed the case, MGW, NC, MP, ROH and SS collected and analyzed the data, MGW and NC wrote the preliminary draft of the manuscript and all authors supplied comments and corrections, SS is the guarantor. All authors read and approved the final manuscript.

\section{Competing interests}

The authors declare that they have no competing interests.

Received: 29 May 2011 Accepted: 29 November 2011

Published: 29 November 2011

\section{References}

1. Corrado D, Basso C, Leoni L, Tokajuk B, Bauce B, Frigo G, Tarantini G, Napodano M, Turrini P, Ramondo A, Daliento L, Nava A, Buja G, lliceto S,
Thiene G: Three-dimensional electroanatomic voltage mapping increases accuracy of diagnosing arrhythmogenic right ventricular cardiomyopathy/dysplasia. Circulation 2005, 111(23):3042-50

2. Maron BJ, Epstein SE, Roberts WC: Causes of sudden death in competitive athletes. J Am Coll Cardiol 1986, 7(1):204-14.

3. Elliott $P$, Andersson $B$, Arbustini $E$, Bilinska Z, Cecchi F, Charron $P$, Dubourg O, Kuhl U, Maisch B, McKenna WJ, Monserrat L, Pankuweit S, Rapezzi C, Seferovic P, Tavazzi L, Keren A: Classification of the cardiomyopathies: a position statement from the European Society Of Cardiology Working Group on Myocardial and Pericardial Diseases. Eur Heart J 2008, 29(2):270-6.

4. Maron BJ, Shirani J, Poliac LC, Mathenge R, Roberts WC, Mueller FO: Sudden death in young competitive athletes. Clinical, demographic, and pathological profiles. Jama 1996, 276(3):199-204.

5. Van Camp SP, Bloor CM, Mueller FO, Cantu RC, Olson HG: Nontraumatic sports death in high school and college athletes. Med Sci Sports Exerc 1995, 27(5):641-7.

6. Basavarajaiah S, Boraita A, Whyte G, Wilson M, Carby L, Shah A, Sharma S: Ethnic differences in left ventricular remodeling in highly-trained athletes relevance to differentiating physiologic left ventricular hypertrophy from hypertrophic cardiomyopathy. J Am Coll Cardiol 2008, 51(23):2256-62.

7. Whyte GP, George K, Sharma S, Firoozi S, Stephens N, Senior R, McKenna WJ: The upper limit of physiological cardiac hypertrophy in elite male and female athletes: the British experience. Eur J Appl Physiol 2004, 92(4-5):592-7.

8. Pelliccia A, Maron BJ, Spataro A, Proschan MA, Spirito P: The upper limit of physiologic cardiac hypertrophy in highly trained elite athletes. $N$ Engl J Med 1991, 324(5):295-301.

9. Kramer CM, Barkhausen J, Flamm SD, Kim RJ, Nagel E: Standardized cardiovascular magnetic resonance imaging (CMR) protocols, society for cardiovascular magnetic resonance: board of trustees task force on standardized protocols. J Cardiovasc Magn Reson 2008, 10(1):35.

10. Rudolph A, Abdel-Aty H, Bohl S, Boye P, Zagrosek A, Dietz R, Schulz Menger J: Noninvasive detection of fibrosis applying contrast-enhanced cardiac magnetic resonance in different forms of left ventricular hypertrophy relation to remodeling. J Am Coll Cardiol 2009, 53(3):284-91.

11. Maron BJ, Wesley YE, Arce J: Hypertrophic cardiomyopathy compatible with successful completion of the marathon. Am J Cardiol 1984, 53(10):1470-1.

12. Pelliccia A, Maron BJ, Culasso F, Di Paolo FM, Spataro A, Biffi A, Caselli G, Piovano P: Clinical significance of abnormal electrocardiographic patterns in trained athletes. Circulation 2000, 102(3):278-84.

13. Pelliccia A, Di Paolo FM, Quattrini FM, Basso C, Culasso F, Popoli G, De Luca R, Spataro A, Biffi A, Thiene G, Maron BJ: Outcomes in athletes with marked ECG repolarization abnormalities. N Engl J Med 2008, 358(2):152-61.

14. Rawlins J, Carre F, Kervio G, Papadakis M, Chandra N, Edwards C, Whyte GP, Sharma S: Ethnic differences in physiological cardiac adaptation to intense physical exercise in highly trained female athletes. Circulation 2010, 121(9):1078-85.

15. Magalski A, Maron BJ, Main ML, McCoy M, Florez A, Reid KJ, Epps HW, Bates J, Browne JE: Relation of race to electrocardiographic patterns in elite American football players. J Am Coll Cardiol 2008, 51(23):2250-5.

16. Wilson MG, Chatard JC, Hamilton B, Prasad SK, Carre F, Whyte GP, Chalabi H: Significance of deep T-wave inversions in an asymptomatic athlete with a family history of sudden death. Clin J Sport Med 2011, 21(2):138-40.

17. Wilson M, Chatard JC, Carre F, Hamilton B, Whyte G, Sharma S, Chalabi H: Prevalence of Electrocardiographic Abnormalities in West-Asian and African Male Athletes. Br J Sports Med 2011.

18. Rawlins J, Bhan A, Sharma S: Left ventricular hypertrophy in athletes. Eur J Echocardiogr 2009.

19. Bellenger NG, Francis JM, Davies CL, Coats AJ, Pennell DJ: Establishment and performance of a magnetic resonance cardiac function clinic. $J$ Cardiovasc Magn Reson 2000, 2(1):15-22.

20. Bellenger NG, Grothues F, Smith GC, Pennell DJ: Quantification of right and left ventricular function by cardiovascular magnetic resonance. Herz 2000, 25(4):392-9.

21. Rickers C, Wilke NM, Jerosch-Herold M, Casey SA, Panse P, Panse N, Weil J, Zenovich AG, Maron BJ: Utility of cardiac magnetic resonance imaging in 
the diagnosis of hypertrophic cardiomyopathy. Circulation 2005, 112(6):855-61.

22. Maron BJ, Lindberg J, Haas TS, Kitner C, Lesser JR: Disparity between unusual left ventricular morphology and clinical presentation and course in hypertrophic cardiomyopathy. Am J Cardiol 2010, 105(11):1643-4.

23. McCrohon JA, Moon JC, Prasad SK, McKenna WJ, Lorenz CH, Coats AJ, Pennell DJ: Differentiation of heart failure related to dilated cardiomyopathy and coronary artery disease using gadoliniumenhanced cardiovascular magnetic resonance. Circulation 2003, 108(1):54-9.

24. Moon JC, Fisher NG, McKenna WJ, Pennell DJ: Detection of apical hypertrophic cardiomyopathy by cardiovascular magnetic resonance in patients with non-diagnostic echocardiography. Heart 2004, 90(6):645-9.

25. Popovic ZB, Kwon DH, Mishra M, Buakhamsri A, Greenberg NL, Thamilarasan M, Flamm SD, Thomas JD, Lever HM, Desai MY: Association between regional ventricular function and myocardial fibrosis in hypertrophic cardiomyopathy assessed by speckle tracking echocardiography and delayed hyperenhancement magnetic resonance imaging. J Am Soc Echocardiogr 2008, 21(12):1299-305.

26. Maron BJ, McKenna WJ, Danielson GK, Kappenberger LJ, Kuhn HJ, Seidman CE, Shah PM, Spencer WH, Spirito P, Ten Cate FJ, Wigle ED: American College of Cardiology/European Society of Cardiology clinical expert consensus document on hypertrophic cardiomyopathy. A report of the American College of Cardiology Foundation Task Force on Clinical Expert Consensus Documents and the European Society of Cardiology Committee for Practice Guidelines. J Am Coll Cardiol 2003, 42(9):1687-713.

27. Richard P, Charron P, Carrier L, Ledeuil C, Cheav T, Pichereau C, Benaiche A, Isnard R, Dubourg O, Burban M, Gueffet JP, Millaire A, Desnos M, Schwartz K, Hainque B, Komajda M: Hypertrophic cardiomyopathy: distribution of disease genes, spectrum of mutations, and implications for a molecular diagnosis strategy. Circulation 2003, 107(17):2227-32.

28. Wilson M, O'Hanlon R, Prasad S, Deighan A, Macmillan P, Oxborough D, Godfrey R, Smith G, Maceira A, Sharma S, George K, Whyte G: Diverse patterns of myocardial fibrosis in lifelong, veteran endurance athletes. J Appl Physiol 2011, 110(6):1622-6.

29. Corrado D, Basso C, Pavei A, Michieli P, Schiavon M, Thiene G: Trends in sudden cardiovascular death in young competitive athletes after implementation of a preparticipation screening program. Jama 2006, 296(13):1593-601.

30. Maron BJ, Ackerman MJ, Nishimura RA, Pyeritz RE, Towbin JA, Udelson JE: Task Force 4: HCM and other cardiomyopathies, mitral valve prolapse, myocarditis, and Marfan syndrome. J Am Coll Cardiol 2005, 45(8):1340-5.

31. Pelliccia A, Fagard R, Bjornstad HH, Anastassakis A, Arbustini E, Assanelli D, Biffi A, Borjesson M, Carre F, Corrado D, Delise P, Dorwarth U, Hirth A, Heidbuchel H, Hoffmann E, Mellwig KP, Panhuyzen-Goedkoop N, Pisani A, Solberg EE, van-Buuren F, Vanhees $L$, Blomstrom-Lundqvist C, Deligiannis $A$, Dugmore D, Glikson M, Hoff PI, Hoffmann A, Hoffmann E, Horstkotte D, Nordrehaug JE, Oudhof J, McKenna WJ, Penco M, Priori S, Reybrouck T, Senden J, Spataro A, Thiene G: Recommendations for competitive sports participation in athletes with cardiovascular disease: a consensus document from the Study Group of Sports Cardiology of the Working Group of Cardiac Rehabilitation and Exercise Physiology and the Working Group of Myocardial and Pericardial Diseases of the European Society of Cardiology. Eur Heart J 2005, 26(14):1422-45.

32. Heidbuchel H, Corrado D, Biffi A, Hoffmann E, Panhuyzen-Goedkoop N, Hoogsteen J, Delise P, Hoff PI, Pelliccia A: Recommendations for participation in leisure-time physical activity and competitive sports of patients with arrhythmias and potentially arrhythmogenic conditions. Part II: ventricular arrhythmias, channelopathies and implantable defibrillators. Eur J Cardiovasc Prev Rehabil 2006, 13(5):676-86.

33. Moon JC, McKenna WJ, McCrohon JA, Elliott PM, Smith GC, Pennell DJ: Toward clinical risk assessment in hypertrophic cardiomyopathy with gadolinium cardiovascular magnetic resonance. J Am Coll Cardiol 2003, 41(9):1561-7.

34. O'Hanlon R, Grasso A, Roughton M, Moon JC, Clark S, Wage R, Webb J, Kulkarni M, Dawson D, Sulaibeekh L, Chandrasekaran B, Bucciarelli-Ducci C, Pasquale F, Cowie MR, McKenna WJ, Sheppard MN, Elliott PM, Pennell DJ, Prasad SK: Prognostic significance of myocardial fibrosis in hypertrophic cardiomyopathy. J Am Coll Cardiol 2010, 56(11):867-74.
35. Kawara T, Derksen R, de Groot JR, Coronel R, Tasseron S, Linnenbank AC, Hauer RN, Kirkels H, Janse MJ, de Bakker JM: Activation delay after premature stimulation in chronically diseased human myocardium relates to the architecture of interstitial fibrosis. Circulation 2001, 104(25):3069-75.

36. Rubinshtein R, Glockner JF, Ommen SR, Araoz PA, Ackerman MJ, Sorajja P, Bos JM, Tajik AJ, Valeti US, Nishimura RA, Gersh BJ: Characteristics and clinical significance of late gadolinium enhancement by contrastenhanced magnetic resonance imaging in patients with hypertrophic cardiomyopathy. Circ Heart Fail 2010, 3(1):51-8.

37. Maron $\mathrm{BJ}$ : Contemporary insights and strategies for risk stratification and prevention of sudden death in hypertrophic cardiomyopathy. Circulation 2010, 121(3):445-56.

doi:10.1186/1532-429X-13-77

Cite this article as: Wilson et al: Hypertrophic cardiomyopathy and ultra-endurance running - two incompatible entities? Journal of Cardiovascular Magnetic Resonance 2011 13:77.

\section{Submit your next manuscript to BioMed Central and take full advantage of:}

- Convenient online submission

- Thorough peer review

- No space constraints or color figure charges

- Immediate publication on acceptance

- Inclusion in PubMed, CAS, Scopus and Google Scholar

- Research which is freely available for redistribution 